COMMENTARY

\title{
Altruism: Brief Review of Current Opinions and Implications on Community Emergency Medicine
}

\author{
Oshionwu EJ1 and Nwose EU ${ }^{2,3^{*}}$ \\ ${ }^{1}$ Standards Compliance Coordinator, California Health Care Facility, USA \\ ${ }^{2} V /$ Professor, Novena University, Nigeria \\ ${ }^{3}$ School of Community Health, Charles Sturt University, Australia
}

*Corresponding author: Dr. Ezekiel Uba Nwose, V/Professor, Public \& Community Health, Novena University, Ogume, Nigeria; School of Community Health, Charles Sturt University, 346 Leeds Pde, Orange Campus, NSW 2800, Australia, Tel: +61-263657282, Fax: $+61-263657282$

\begin{abstract}
There are several theories on altruism including the concept of pseudo-altruism. The latter constitute divergent opinion around egoism and socioeconomic status (SES). Review has identified that the conflict between altruistic and pseudo-altruistic theoretical approaches can be resolved by combining elements from both concepts. The objective of this commentary is to advance (1) That there is 'benefit to the helping altruistic individual in all altruism theories; and (2) A unifying viewpoint in terms of benefit that while every altruistic act is an adaptive humanitarian behaviour that benefits another person who is primarily the beneficiary, the benefactor always has a benefit that is secondary. Thus, every genuine act of altruism can be easily erroneously deconstructed and reconstructed as pseudo-altruism, which disparages the benefactor and undermines the primary benefit. SES is associated with altruism, and the concept of socioeconomic inequalities in healthcare delivery is alluded to be a reflection of degeneration of altruistic behaviour in society. The famous Good Samaritan story is empirically reviewed to translate altruistic response of individuals of higher SES compared to those of lower counterpart in community health. The implications for health of individuals at the family level, and community-level emergency is briefly espoused. The correlation to current medical practice regarding treating patients with or without health insurance is drawn. A classical workplace experience is also presented to illustrate the current state of intimidation that influences altruism in contemporary healthcare practice.
\end{abstract}

\section{Keywords}

Benefactor-beneficiary, Critical care, Deconstruction and reconstruction

\section{Introduction}

\section{Theories of altruism}

The evolutionary theory of Charles Darwin hypothesized that altruism occur because it contributes to the survival of the species [1-3]. Extending this idea, socio-biologist has proffered that there is a genetic selection over generations for self-sacrificial behaviour, because such helping behaviour increases the probability of species' survival in the long run [4]. Several other theories have been and are still being propagated.

The equity theory suggests that we help others because people accept help from them, thus achieving balance or parity in our interpersonal relationships [5]. The outcome or target of achieving balance or parity implies that the theory is premised upon the inherent needs for humans to strive to be at equilibrium with another. Negative affect theory suggests that seeing an emergency in progress produce unpleasant physiological and emotional arousal that can be reduced by engaging in helping behaviour [6-13]. The empathy theory argues that altruism is due to the ability to deeply understand the feelings and experience of others. Instead of being precipitated by mere seeing, it represents a genuine feeling of concern even when it does not reduce the helper's distress [14-17]. Further,

Citation: Oshionwu EJ, Nwose EU (2019) Altruism: Brief Review of Current Opinions and Implications on Community Emergency Medicine. Int J Crit Care Emerg Med 5:066. doi.org/10.23937/24743674/1510066

Accepted: January 23, 2019: Published: January 25, 2019

Copyright: (C) 2019 Oshionwu EJ, et al. This is an open-access article distributed under the terms of the Creative Commons Attribution License, which permits unrestricted use, distribution, and reproduction in any medium, provided the original author and source are credited. 
the normative theories suggest that society establishes a norm of prosocial behaviour and include the concepts of reciprocity and social responsibility. The reciprocity or the golden rule norm dictates the proverbial do unto others as you would have them do unto you [18]. However, the application of this social responsibility norm tends to be selective. For instance, it is more likely to help a person whose problem seems to stem from circumstances beyond her/his control relative to own fault [19].

Altogether, five theories are highlighted to explain altruistic behaviour. These theories are seemingly divergent opinions around the benefits of an altruism act, especially including the motivation of the helper that drives the concepts of egoism and pseud-altruism. Further, each theory has implied contribution of socioeconomic status (SES), i.e. helpeehelper relationship being a condition of advantageddisadvantaged disparity in every given circumstance of altruism. Review has identified that the conflict between altruistic and pseudo-altruistic theoretical approaches can be resolved by combining elements from both concepts [3]. Therefore, the objective of this commentary is to articulate the 'benefits to the helper in each altruism theories' and advance unifying viewpoint in terms of benefit that every genuine act of altruism can be easily erroneously deconstructed and reconstructed as pseudo-altruism.

SES is associated with altruism, and the concept of socioeconomic inequalities in healthcare delivery is alluded to be a reflection of degeneration of altruistic behaviour society. Therefore, two case scenarios are presented. First is to illustrate how a genuine altruistic act is voluntary yet could be erroneously deconstructed and reconstructed as pseudo-altruism as well as the opportunities to practice similar acts of altruism being almost abolished by regulations. Second is to highlight how reciprocal theory of altruism prosocial behaviour makes altruism and pseudo-altruism are inseparable in the healthcare industry.

\section{The Case Scenarios}

\section{Good samaritan story}

"A man was going down from Jerusalem to Jericho, when he was attacked by robbers. They stripped him of his clothes, beat him and went away, leaving him half dead. A priest happened to be going down the same road, and when he saw the man, he passed by on the other side. So too, a Levite, when he came to the place and saw him, passed by on the other side. But a Samaritan, as he travelled, came where the man was; and when he saw him, he took pity on him. He went to him and bandaged his wounds, pouring on oil and wine. Then he put the man on his own donkey, brought him to an inn and took care of him. The next day he took out two denarii and gave them to the innkeeper. 'Look after him', he said, 'and when I return, I will reimburse you for any extra expense you may have'". (Luke 10: 30-35 New International Version).

\section{Disability workplace story}

A man working in a disability healthcare setting was accused of sexual assault by autistic boy who had established relationship with female staff. The story was that client preferred lady carers to give him bath. On the said occasion, a male staff offered to give the client bath and this was turned down by the client. Further, the client reportedly felt sad that the male staff should have known his preference, and client's family misinterpreted it as sexual assault. It took dispute resolution process to clear the male staff of any wrong doing [20].

\section{Empirical Review}

\section{Altruism vs. Ego}

A systematic literature review presenting conflicting theoretical arguments from both the pseudo-altruistic (selfishly motivated) and altruistic approaches had quite recently been performed and ways to overcome the conflict were suggested [3]. Pertinent in the review is the articulation of evolutionary theory of altruism that humans are naturally egoistic and hedonistic with intent to seek pleasure and avoid pain. The authors cited multiple works to expatiate that the concept of altruism was actually introduced in order to distinguish this form of altruistic behaviour from ego; and that egoism is pseudo-altruism.

Apparently, what is missing in the discourse is the fact that benefit to the helper can always be seen to underlie all the seemingly different theories of altruism (Table 1). The argument or view-point being brought to the fore is that if elements of benefit to the helper translates a help into egoism or pseudo-altruism, then altruism and egoism may be inseparable. On one hand, both egoism or the evolutionary theory of altruism fosters self-satisfaction and/or self-esteem hence they

Table 1: Benefits to the helper in each altruism theories.

\begin{tabular}{|l|l|l|}
\hline Theory & Perspective & Benefit to helper \\
\hline Evolutional & Genetic selection for survival of species & Survival of species \\
\hline Equity & Equity in interpersonal relationships & Expect help from others \\
\hline Negative affect & Stimulation by negative emotions & Emotional healing \\
\hline Empathy & Genuine feelings of concern & Appreciation, respect \\
\hline Normative (reciprocity) & "Do unto others as you like them do to you” & Reciprocal expectation of favour \\
\hline Normative (pro-social) & Socio-cultural expectation with antidote & Hidden rewards; unwritten 'penalties vs. reputation' \\
\hline
\end{tabular}


can be pseudo-altruism. On the other hand, the negative affect theory suggests that unpleasant physiological and emotional arousal is reduced by engaging in helping behaviour. Thus, the helper has some benefits as in evolutionary or pseudo-altruism theories.

\section{Reviewing of the Good Samaritan story}

\section{Ego}

The proponents of pseudo-altruism may identify that the Good Samaritan may be egoistic with underlying selfish motivation - e.g. reducing the unpleasant emotions elicited by the sight. Yet, the negative affect theorists may posit that "when he saw him, he took pity on him" means unpleasant emotional arousal and thus altruistic behaviour. It is noteworthy that three persons saw the same unpleasant emotion-arousing robbery scene; and adopted different methods to reduce the unpleasantness. That is, only the Good Samaritan's behaviour benefited the victim. Therefore, while the negative affect response that benefited the critical and emergency medical need of the wounded victim must be appreciated as altruism, it would be cynical to contextualize the benefit derived by the Good Samaritan as egoism or pseudo-altruism. Such contextualization amounts to undermining of the primary benefit as well as a deconstruction and reconstruction of genuine act of altruism into pseudo-altruism. It will be disparaging of a voluntary act of help in an occasion of critical care need, which is capable of changing the helper's belief thereby altering the behavioural change wheel in the negative direction e.g. becoming demotivated to help again as per normal physiological stress response to being criticized.

\section{Socio-economic status (SES)}

There is indication that SES is associated with altruism [21], and the concept of socioeconomic inequalities in health being a reflection of society [22]. It may be argued that the Good Samaritan man had the capacity (e.g. bandage and other first aid materials; plus donkey to transport the 'critical and emergency' victim to hospital). Hence of higher SES compared to the Levite and the Priest. However, it is pertinent to note that the Good Samaritan man.

1. Suspended his own travel to stay with the victim at the hospital until the next day, but neither the Levite nor the Priest suspended their mission to try to see what could be done such as raising alarm to call for help.

2. Never had enough money to pay the bill; but there was no indication that the Levite or the Priest lacked two denarii, which the Inn Keeper accepted as initial payment.

Resonant with this pertinent note is the situation in community medicine research. Arguably, the problem in recruiting research participants is that those who decline consent have a relatively higher SES, compared with consenters who have higher levels of altruism and perceived the potential for enhanced care $[23,24]$. It is arguable that this problem is based on theories developed through the research on altruism and the volunteer bias; and that there is no empirical evidence or substantiation. At this instance of 'robbery victim' requiring emergency care, the altruistic behaviour of the Good Samaritan is not necessarily a factor of SES, but voluntarism for the primary benefit of another person.

Moreover, a fourth person in the scenario who is most often ignored in the Good Samaritan story is the innkeeper - the actual Internal Medicine practitioner. Of particular relevance in this discourse is agreeing to provide healthcare service in trust. In modern society of mistrust, healthcare facilities have the challenge of providing service without clear assurance of payment [25]. This has underpinned healthcare management systems involving health insurance policies whereby lower SES 'uninsured' patients are put on waiting list, while the higher SES 'insured' individual with similar healthcare need is attended immediately.

\section{Review of the Disability Healthcare Workplace Story}

\section{Ego}

It is known that when a disability client is unable to get 24 hours/day care from family, agency-supported carers provide the alternative $[26,27]$. This is especially in developed countries such as Australia, and this caregiving is an altruistic service [27]. Suffice to note that "caregivers who provide 24 hour per day care experience caregiver burden" [26]. Considering motivation, cynics may very easily identify being paid as monetary impetus for providing care i.e. to justify that a healthcare worker is pseudo-altruistic. Thus, genuine acts of voluntarism vis-à-vis altruistic behaviour by healthcare workers may be easily deconstructed and reconstructed as ego, pseudo-altruism, or simply competent. Yet, the reciprocal theory of altruism indicates that the costs of altruistic behaviour are offset by reciprocated benefits to the benefactor. This is resonant with the prosocial behaviour, because evolution has programmed us (regardless of SES) to expect help from others - re: The proverbial do unto others as you would have them do unto you [18].

The point of emphasis here is that altruism can very easily be viewed as pseudo-altruism, especially in the healthcare industry. Otherwise, true altruism does not exist, because there is 'benefit to the helping altruistic individual in all altruism theories'. The healthcare industry is functional on economics, not voluntarism. Perhaps, it is confounding that the healthcare industry functions on economics, not voluntarism. Quite occult is that "there is little or no emotional or financial reward for voluntary addenda to patient care and that such 
behaviours may actually be punished" [28], which tends to nullify indication of diminishing altruism in the healthcare industry $[25,28,29]$. In the "Disability Workplace" case scenario presented, the healthcare worker would have suffered emotional trauma due to the accusation and dispute process that ensued. While the client's understanding of the sexual assault may have arisen from the reality of existing sex predators, the emotional trauma suffered by the healthcare worker implies psychological form of punishment.

\section{Socio-economic status (SES)}

In the normative theories of altruism, the society establishes a norm of pro-social behaviour or cultural expectation e.g. do unto others as you would have them do unto you [18]. Therefore, there is often hidden rewards as well as unwritten penalties associated with such norms, which the advocates of pseudo-altruism may posit as motivation. However, The social responsibility norm is vis-a-vis cultural expectation that people will help those who need help and who depend on them without specific reward in return. The recipient may not reciprocate if he feels that the help was not appropriate or that it was not given voluntarily. The golden rule norm thus works in limited circumstances [30,31]. What is unknown, at least to the proponents of pseudoaltruism, is how the deconstruction and reconstruction of altruistic services of healthcare providers affects public health service. The case presented exemplifies how SES context of altruism fails in critical care medicine. A healthcare worker volunteered to help give bath, but the voluntarism being misinterpreted and prosecuted i.e. a helpee rejecting voluntary help from the helper in a way that discourage potential voluntarism in similar circumstance.

\section{Implications for Healthcare Delivery}

\section{Individual family levels}

There are at least two implications to the health of individuals at the family level. One is the growing concern on aged-care, which is mixed up with egalitariani$\mathrm{sm}$, policies and professionalism. This was articulated in "...the challenge for our generation to face up to our responsibilities because we are a caring, compassionate and egalitarian society" [32]. While aged-care is an altruistic service provided by relatives in some societies such as Nigeria and culturally dictated by the normative theory of altruism, it is a paid nursing service governed by professional codes in some developed societies.

As much as $40 \%$ of healthcare practitioners think that individual altruism had no role in solving public health problems [33]. That is, it is now commonly believed that paid healthcare services do not construe true altruism. This raises the query whether the fourth person (Innkeeper) in the Good Samaritan story demonstrated true altruism; or if a contemporary Private General Practitioner accepts to treat a patient without health insurance is still altruistic - i.e. for agreeing to provide healthcare service in trust; relative to our modern society of mistrust Where most healthcare facilities have the common policy of providing service only upon clear assurance of payment. The opinion being propagated here is that the action of the innkeeper who admitted the patient without a documented or valid insurance constitutes true altruism, which need to be appreciated in our modern day.

What is quite apparent is that being of higher SES may provide access to necessary healthcare services, but this does not mean altruistic care that involves voluntarily doing beyond one's designated duties. Yet, considering SES in the case of a carer accused of abusing client, it is arguable whether an employee carer:

$>$ Goes to work with a sense of altruism.

$>$ Is appreciated when 'healthcare' is performed with a sense of altruism.

\section{Community Healthcare Practice Level}

In the Good Samaritan story, travelling with first-aid kits is probably a factor to note. Whether the relevantly qualified healthcare professionals do carry first-aid kits in their cars to perform opportunistic acts of altruism is something to consider in terms of behavior. The concept of behavioural change wheel includes factors of capacity, motivation and opportunity. The concept in this instance connotes that a qualified healthcare professional may be unable to offer altruistic help if the capacity to do so is lacking.

Yet, some restrictive policies may have restricted the Good Samaritan from applying the first-aid at such critical care scene. For instance, modern day laws may warrant the Good Samaritan to keep the criminal scene intact, which implies leaving the victim until the police arrives. A critical inquiry into the development of such restrictive policies may have arisen as a result of subjective and disparaging interpretations given to acts of altruism. For instance, the altruistic person could be abused with conjectures of obscuring evidence, sexual assault or the actual robbery. It could have been asked if the Good Samaritan has authorization, medical qualification or legal license to provide first-aid care.

Further, there may be provisions to call emergency line (e.g. 000 in Australia and 911 in USA) for ambulance services. Whether those who call the emergency lines for other person's emergency are being altruistic is arguable. If the actions of the priest and the Levite in the Good Samaritan story are distasteful, it is logical that calling emergency lines for another person is altruistic. Further, it is an ongoing argument whether the Ambulance workers who respond to critical and emergency calls with empathy are appreciated as being altruistic or pseudo-altruistic. The opinion submitted here is that there is always a benefit to the helper in every altruistic behaviour. Hence, empathic service that 
primarily benefits a patient is in line with the empathy theory of altruism, which should not be deconstructed and reconstructed into pseudo-altruism; especially as being paid for the service resonates with reciprocated benefit to the benefactor in some other theories of altruism.

\section{Conclusion}

There is suggestion that "theoretical models would greatly benefit from being inclusive rather than exclusive in allowing for the possibility of co-existing motivational drivers (egoistic and altruistic) ... The conflict between pseudo-altruistic and altruistic theoretical approaches can be minimized or resolved by combining elements from both sides of the debate" [3]. Altruism may be redefined as an adaptive humanitarian behaviour that benefits another person if it is done by the benefactor for the good of primarily the beneficiary. However, the altruistic person always has its own benefit that is secondary and either direct or indirect. In this unifying redefinition, the motivation of the benefactor is either (1) Apparent as in evolutional, negative affect, and normative reciprocal theories or (2) Covert as in empathy, equity and normative prosocial theories. The secondary benefit to the altruistic person being ever present needs to be acknowledged in every theory of altruism that may be used to explain the humanitarian behaviour (Table 1). The emphasis here is that if primary beneficiary and theorem are identifiable, then elucidating the secondary benefit to substantiate egoism or pseudo-altruism is disparagement of the benefactor that is capable of limiting altruistic behaviour as the potential outcome. It is known that a bias towards pseudo-altruism exists in the field of medicine The point of this paper is that such bias towards pseudo-altruism needs to be appraised and readdressed as a step to revaluation of altruism in the health industry. In the concept of behavioural change wheel, it is hoped that the revaluation will change the belief system, which in turn will drive motivation to enhance altruism in the industry.

\section{References}

1. Dugatkin LA (2007) Inclusive fitness theory from Darwin to Hamilton. Genetics 176: 1375-1380.

2. Wyatt GA, West SA, Gardner A (2013) Can natural selection favour altruism between species? J Evol Biol 26: 1854-1865.

3. Feigin S, Owens G, Goodyear-Smith F (2014) Theories of human altruism: A systematic review. Annals of Neuroscience and Psychology 1: 1-8.

4. Wilson EO (1978) What is Sociobiology? In: Gregory MS, Silvers A, Sutch D, Sociobiology and Human Nature: An Interdisciplinary Critique and Defense. CA: Jossey-Bass, San Francisco, USA, 1-12.

5. Wagstaff G (1998) Equity, justice, and altruism. Curr Psychol 17: 111-134.
6. Oakley BA (2013) Concepts and implications of altruism bias and pathological altruism. Proc Natl Acad Sci USA 110: 10408-10415.

7. Fehr E, Rockenbach B (2003) Detrimental effects of sanctions on human altruism. Nature 422: 137-140.

8. Berkowitz L, Thome P (1987) Pain expectation, negative affect, and angry aggression. Motiv Emot 11: 183-193.

9. Crawford JR, Henry JD (2004) The positive and negative affect schedule (PANAS): Construct validity, measurement properties and normative data in a large non-clinical sample. Br J Clin Psychol 43: 245-265.

10. Brdar I (2014) Positive and Negative Affect Schedule (PANAS). In: Michalos A, Encyclopedia of Quality of Life and Well-Being Research. Springer Netherlands, 49184920.

11. Leung S, Lee A (2014) Negative Affect. In: Michalos A, Encyclopedia of Quality of Life and Well-Being Research, Springer Netherlands, 4302-4305.

12. Chang HY, Teng Cl, Chu TL, Chang HT, Hsu WH (2012) Impact of nurse agreeableness and negative mood of nursing supervisors on intention to help colleagues. J Adv Nurs 68: 636-646.

13. Dulin PL, Hill RD (2003) Relationships between altruistic activity and positive and negative affect among low-income older adult service providers. Aging Ment Health 7: 294299.

14. Davis MH, Luce C, Kraus SJ (1994) The heritability of characteristics associated with dispositional empathy. J Pers 62: 369-391.

15. Eisenberg N, Eggum ND, Di Giunta L (2010) Empathyrelated responding: Associations with prosocial behavior, aggression, and intergroup relations. Soc Issues Policy Rev 4: 143-180.

16. Roberts W, Strayer J (1996) Empathy, emotional expressiveness and prosocial behaviour. Child Development 67: 449-470.

17. Tone EB, Tully EC (2014) Empathy as a "risky strength": A multilevel examination of empathy and risk for internalizing disorders. Dev Psychopathol 26: 1547-1565.

18. Wilke H, Lanzetta JT (1970) The obligation to help: The effects of amount of prior help on subsequent helping behavior. Journal of Experimental Social Psychology 6: 488-493.

19. Meyer JP, Mulherin A (1980) From attribution to helping: An analysis of the mediating effects of affect and expectancy. $J$ Pers Soc Psychol 39: 201-210.

20. Vernon J (2016) Police lacked evidence to charge carer accused of abusing autistic teen, royal commission told. ABC News Online.

21. Abasolo I, Tsuchiya A (2014) Egalitarianism and altruism in health: Some evidence of their relationship. Int $\mathrm{J}$ Equity Health 13: 13.

22. Marmot M (2012) Why should the rich care about the health of the poor? CMAJ 184: 1231-1232.

23. Hoberman A, Shaikh N, Bhatnagar S, Haralam MA, Kearney DH, et al. (2013) Factors that influence parental decisions to participate in clinical research: consenters vs nonconsenters. JAMA Pediatr 167: 561-566.

24. Williams MM, Scharff DP, Mathews KJ, Hoffsuemmer JS, Jackson P, et al. (2010) Barriers and facilitators of African American participation in Alzheimer disease biomarker research. Alzheimer Dis Assoc Disord 24: S24-S29. 
25. Jones $R$ (2002) Declining altruism in medicine. Understanding medical altruism is important in workforce planning. BMJ 324: 624-625.

26. Rhoades DR, McFarland KF (2000) Purpose in life and selfactualization in agency-supported caregivers. Community Ment Health J 36: 513-521.

27. Rhoades DR, McFarland KF (1999) Caregiver meaning: A study of caregivers of individuals with mental illness. Health Soc Work 24: 291-298.

28. Fleming K (2002) Declining altruism in medicine. Good service is voluntary. BMJ 324: 1398.

29. Workman S (2002) Declining altruism in medicine. Altruism is not equal to self sacrifice. BMJ 324: 1398.
30. Graziano WG, Habashi MM (2010) Motivational processes underlying both prejudice and helping. Pers Soc Psychol Rev 14: 313-331.

31. McGrath MP, Brown BC (2008) Developmental differences in prosocial motives and behavior in children from lowsocioeconomic status families. J Genet Psychol 169: 5-20.

32. Keaney G (2009) Australian Nursing Federation Budget submission 2010-2011: Introduction.

33. Tharakan LJ, Elencheral AL, Karthiga M, Kumaran V, Rakesh PS, et al. (2012) Medical students' views on the migration of doctors: Self-interest vs altruism. Indian J Med Ethics 9: 249-251. 